\title{
Phototoxicity of Ultraviolet (UV) Radiation: Evaluation of UV-Blocking Efficiency of Intraocular Lens (IOL) Materials Using Retinal Cell Culture and in vitro Bioassays
}

\author{
H.Y. Youn* , A.P. Cullen, B.R. Chou and J.G. Sivak \\ School of Optometry, University of Waterloo, Waterloo, N2L 3G1, Ontario, Canada
}

\begin{abstract}
This work involves the evaluation of UV blocking efficiency of commercially available intraocular lens (IOL) materials using a retinal cell culture and a biological in vitro model that was developed in a previous study, as an effort to examine the sensitivity of this in vitro approach for evaluating toxicity of UV radiation on the retinal pigment epithelial cells. The human retinal pigment epithelial (RPE) cell line, ARPE-19, was cultured, and cells were irradiated with broadband UVB radiations at energy levels of 0.2 and $0.4 \mathrm{~J} / \mathrm{cm}^{2}$. Some treated cells were not shielded from the radiation while others were shielded using two thicknesses $(0.9$ and $1.5 \mathrm{~mm})$ of IOL material. After irradiation, cellular viability, mitochondrial distribution, nuclei morphology, and phagocytotic activity were analyzed using the Alamar blue assay, Rhodamine 123 staining, the Hoechst assay, and a phagocytotic activity assay. The results demonstrate that UVB radiation can cause significant decreases in RPE cell viability as well as in phagocytotic activity. Also, the results show that UVB radiation can induce the degradation of DNA and mitochondria in cultured RPE cells. However, the two different thickness IOL material sheets $(0.9$ and $1.5 \mathrm{~mm})$ showed very effective UV blocking ability, allowing no cellular damage at all. Thus, the finding suggest that these four assays together can be used as a sensitive, and meaningful in vitro biomarker method for evaluating toxicity of UV radiation on RPE cells, and also for examining IOL effectiveness.
\end{abstract}

Keywords: Intraocular lens, Retinal pigment epithelium, UV radiation, Alamar blue assay, Confocal microscopy, Hoechst assay, Phagocytotic activity assay.

\section{INTRODUCTION}

The crystalline lens of the eye is the principal shield against ultraviolet (UV) radiation (between $300 \mathrm{~nm}$ and 400 $\mathrm{nm}$ ), damage to the human retina [1]. Cataract removal is one of the most common operations performed in the United States [2], and generally an intraocular lens (IOL) is replaced in the lens capsule. With the possibility of extending IOL use to phakic eyes for the correction of high myopia, hyperopia, and other nonopacifying conditions, the use of IOLs may increase further still [2]. The first polymethylmethacrylate IOLs transmitted UV in addition to visible light [3]. Ultraviolet radiation is not required for vision but it can harm the retina at acute and intense exposure $[4,5]$. Most IOLs incorporated UV blocking chromophores by 1986 [6]. However, spectrophotometric data show that most of the commercially available, UV-absorbing IOLs currently in use have different properties than the natural crystalline lens in absorbing UV radiation [7-9].

While there are many studies that evaluate the spectral transmission characteristics of various IOLs to verify their anti-UV efficacy $[6,7,10]$, studies showing the cytotoxic effects of UV radiation on retinal cells in terms of cell biology and physiology are few in number. UV radiation can generate free radicals including oxygen-derived species [11], which are known to cause lipid peroxydation of cellular membranes $[12,13]$. Also, it has been shown that UV can

*Address correspondence to this author at the University of Waterloo 200 University Ave. W. Waterloo, Ontario, N2L3G1, Canada; Tel: 1-519-8884567 (ext. 32233); Fax: 1-519-725-0784; E-mail: hyoun@uwaterloo.ca damage DNA, leading to DNA fragmentation $[11,14,15]$, and decrease mitochondrial function $[6,16,17]$.

The objective of the present study is to evaluate the UVblocking efficacy of commercially available IOL materials using a retinal cell culture and a biological in vitro model that was developed in a previous study [18], as an effort to examine the sensitivity of this in vitro approach for evaluating toxicity of UV radiation on the RPE cells. This work involves the exposure of a RPE cell culture to broadband UVB radiation with and without the protection of IOL material flats. Cellular viability, mitochondrial damage, DNA damage, and phagocytotic activity are quantified after exposure.

\section{MATERIALS AND METHODS}

\section{Human RPE Cell Culture}

The human RPE cell line ARPE-19 was obtained from the American Type Culture Collection (ATCC). The cells were cultured in DMEM/Ham's F-12 with L-glutamine and $15 \mathrm{mM}$ HEPES (Mediatech, VA, USA). The medium also contained 10\% fetal bovine serum (Hycolone, UT, USA), and insulin-transferrin-sodium selenite media supplement (ITS supplement) (Sigma, MO, USA) [18]. The cells were plated in T75 or T150 flasks (Falcon, NJ, USA), and allowed to grow until the cultures were confluent. The cells were grown at $37^{\circ} \mathrm{C}$ in a humidified incubator in an atmosphere of $95 \%$ air and $5 \% \mathrm{CO}_{2}$. Confluent cell flasks were passaged every two days using the dissociating agent Trypsin/EDTA solution (Cascade Biologics, OR, USA). The culture and 
conditioned medium were split into three flasks, and an equal volume of fresh medium was added to each flask. Subculturing was usually performed during the log (or exponential) phase when the cells are at their healthiest and are able to adapt to the new environment most efficiently [19].

\section{UV Irradiation of Cultured RPE Cell}

The IOL flats were supplied by Bausch \& Lomb, Rochester New York. They consisted of yellow tinted standard silicone IOL materials (hydrosiliation cured silicone) that were manufactured by cast molding. The flats, measuring 9.0 by $7.0 \mathrm{~cm}$, were large enough to cover 12 cells of a standard 24 cell multi-well plate that contained the cultured cells. Opaque black tape was applied to the periphery of the plate to ensure that only the radiation passing through the silicon flats could reach the cells. Exposure was produced by UVB fluorescence tubes (cat. No F15T8/UVB; Microlites Scientific, ON, Canada) in a custom designed UV irradiation unit with $4 \% \mathrm{CO}_{2}$ and $96 \%$ membrane-filtered air. The spectral distribution of the UVB fluorescent tubes extends from $290 \mathrm{~nm}$ to about $370 \mathrm{~nm}$ wavelengths, with a peak at around $315 \mathrm{~nm}$. Since the contribution of the wavelengths within the 320 to $370 \mathrm{~nm}$ waveband was only $0.1 \%$, this was ignored. Before irradiation, the irradiance of UVB source was calculated with an Instaspec II diode-array spectroradiometer (Oriel Corporation, CT, USA).

After two days of pre-incubation at $37^{\circ} \mathrm{C}$ to form a confluent cell monolayer, the cells were exposed with 0.2 and $0.4 \mathrm{~J} / \mathrm{cm}^{2}$ of broadband UVB. The cells were incubated for another 48 hours and assays were carried out at 24 and 48 hours after irradiation. In order to minimize absorption of the radiation by phenol red in the medium, a thin layer of medium (about $1.0 \mathrm{~mm}$ ) was left above the cells during UV exposure. Thus, a minor phenol red effect may have influenced the results.

Exposure times for two energy levels $\left(0.2\right.$ and $\left.0.4 \mathrm{~J} / \mathrm{cm}^{2}\right)$ were calculated with the formula: $\mathrm{H}_{\lambda}=t \times \mathrm{E}_{\lambda}$, where $\mathrm{H}_{\lambda}$ is the energy level $\left(\mathrm{J} / \mathrm{cm}^{2}\right), t$ is the exposure time (second), and $\mathrm{E}_{\lambda}$ is the irradiance $\left(\mathrm{W} / \mathrm{cm}^{2}\right)$ [20]. The irradiance measured with a spectroradiometer was $0.000306 \mathrm{~W} / \mathrm{cm}^{2}$, and the exposure times were $10 \mathrm{~min} 54 \mathrm{sec}$ for $0.2 \mathrm{~J} / \mathrm{cm}^{2}$ and $21 \mathrm{~min} 48 \mathrm{sec}$ for $0.4 \mathrm{~J} / \mathrm{cm}^{2}$, respectively. The solar broadband UVB irradiance level (measured in June 1999 @ Waterloo, ON, Canada,) was $0.000276 \mathrm{~W} / \mathrm{cm}^{2}$ [21]. Thus, the irradiance produced by the UVB tubes for this study is comparable to solar spectral irradiance.

\section{Alamar Blue Assay}

The fluorescent indicator dye, Alamar Blue (MEDICORP Inc., Montreal, PQ, Canada) used to evaluate cell viability, is a commercial preparation of the dye resaruzin [22]. For experimental use, it was diluted into the culture medium (mentioned above) without serum to $8 \%(\mathrm{v} / \mathrm{v})$. After two to three days of pre-incubation, the cells were transferred into a sterile flat bottom multi-well cell culture plate (BD Falcon, Franklin Lakes, NJ, USA) for fluorescence measurements. Cell density was adjusted to $1 \times 10^{5}$ cells $/ \mathrm{ml}$ for 48 -well plates and $5 \times 10^{4}$ cells in $500 \mu \ell$ of medium were added to each well [23]. After the irradiation, the culture medium was aspirated from each well, and the cells were rinsed once with culture medium with no serum. Then 100 to $150 \mu \ell$ of assay solution was added to each well containing cells, and the cells were further incubated for one hour to allow the dye to be taken up by the cells. At the end of one hour incubation, the fluorescence measurements were taken with a CytoFluor $^{\mathrm{TM}}$ II fluorescence multi-well plate reader (PerSeptive Biosystems Inc., MA, USA). Before the measurements, the excitation / emission wavelengths settings were adjusted to $530 / 590 \mathrm{~nm}$, with the sensitivity gain set at 50 .

\section{Confocal Microscopy}

Confocal scanning laser microscopy (Carl Zeiss LSM) and two fluorescent dyes (Hoechst 33342 and Rhodamine 123) (Molecular Probes, OR, USA) were used to visualize the changes of RPE cell morphologic features (nucleus and mitochondria of the cells, respectively) after UVB radiation. Hoechst 33342 is a popular cell-permeant nuclear stain that emits blue fluorescence when bound to dsDNA [24]. Rhodamine 123 is a cationic, lipophilic, water-soluble oxonium chloride salt that stains mitochondria in living cells in a membrane potential-dependent fashion [25]. Before irradiation, $1 \times 10^{5}$ cells in $1.5 \mathrm{ml}$ of culture medium were transfered into collagen coated glass bottom culture Petri dishes (MatTek Corp., MA, USA). After the UVB exposure, the cells were then stained for mitochondria and nucleic acid using Rhodamine $123(20 \mathrm{mM})$ and Hoechst 33342 $(10 \mathrm{mg} / \mathrm{ml})$ for $20 \mathrm{~min}$ at $37^{\circ} \mathrm{C}$. A Zeiss confocal laser scanning microscope (CLSM) 510 system attached to an Axiovert 100 microscope with a $40 \times$ water-immersion $\mathrm{C}$ Apochromat objective was used to visualize the effects of the two different dyes.

\section{Hoechst 33342 Stain}

Before the indicated exposure time, cells were plated into 2-well culture slides (BD Falcon, NJ, USA). After the irradiation, cultures were then fixed twice by adding an equal volume (3 4 drops) of Carnoy's fixative (methanol/glacial acetic acid, 3:1). The cells were rinsed with $1 \times$ PBS (phosphate buffered saline), and allowed to air dry. Following the initial fixation, the cell slides were stained with $0.5 \mu \mathrm{g} / \mathrm{ml}$ Hoechst 33342 (Riedel-de Haen Ag Seetz-Hannover) (Molecular Probes, OR, USA) for $10 \mathrm{~min}$. The fluorescent nuclei were visualized using a fluorescence microscope with an ultraviolet (UV) filter (Nikon Optishot microscope, ON, Canada).

\section{Phagocytotic Activity Assay}

Phagocytosis is a critical element in the ability of RPE cells to maintain a healthy retina [26]. Confocal scanning laser microscopy (Carl Zeiss Inc., Jena, Germany) and $0.1 \mu \mathrm{m}$ diameter fluorescent carboxylate-modified microbeads (Molecular Probes, OR, USA) were used to observe the effects of UVB radiation on RPE cell phagocytotic activity. RPE cells were transfered to collagen-coated glass bottom culture Petri dishes (MatTek Corp., MA, USA) with a density of $1.3 \times 10^{5}$ cells in $2 \mathrm{ml}$ of culture medium. After incubating overnight at $37^{\circ} \mathrm{C}, 7 \times 10^{10}$ microbeads (red fluorescent, excitation $580 \mathrm{~nm} /$ emission $605 \mathrm{~nm}$ ) in culture medium were added at a total volume of $2 \mathrm{ml} /$ Petri dish. 
After one day of incubation to allow the beads to be ingested by cells, the microbeads were removed and the adherent cells were washed carefully with fresh culture medium twice to remove undigested particles before confocal observation. The micobeads in the cells were visualized using the confocal microscope, and the intensity of the fluorescent was measured using the Image Analysis toolbox of Matlab 7.1 software package (MathWork Inc., MA, USA).

\section{Statistical Analysis}

Statistical calculations were completed using a two-way repeated measures analysis of variance (ANOVA). A probability value of less then or equal to 0.05 was considered significant.

\section{RESULTS}

\section{Cell Viability}

The Alamar Blue assay readings are presented as percent cell viability relative to the non-UVB exposed cells at three time points: 0-hour (before UV exposure), 24 hours (1-day after UV exposure) and 48 hours (2-day after irradiation). These time points were chosen to permit a time-related evaluation. The results for broadband UVB exposed RPE cells (without IOL protection) showed energy level and time - dependent decreases in cell viability in comparison with the control cells (Fig. 1a and 1b). Although the measurements for 0.2 and $0.4 \mathrm{~J} / \mathrm{cm}^{2}$-exposed cells at the 24-hour time points presented similar loss of cell viability $(64.7 \pm 1.0 \%$ and $61.2 \pm 2.0 \%$, respectively), the Alamar blue assay results for both 0.2 and $0.4 \mathrm{~J} / \mathrm{cm}^{2}$ exposed cells at 48 hour time points clearly showed energy level-dependent decreases in cell viability $(55.5 \pm 2.8 \%$ and $34.6 \pm 7.0 \%$, respectively). The IOL covered cells showed similar viability as control cell groups during the entire culture period, showing very effective UV blocking ability for both IOL material thicknesses of 0.9 and $1.5 \mathrm{~mm}$ (Fig. 1a and 1b).

\section{Mitochondrial Distribution}

Non-irradiated cultured RPE cells (control cells) exhibited no morphological change in mitochondria (first column of Fig. (2), green fluorescence). Overall, increasing the energy level of UVB radiation from 0.2 to $0.4 \mathrm{~J} / \mathrm{cm}^{2}$ resulted in sparser mitochondria, indicating degradation of mitochondria (second column of Fig. (2), green fluorescence). In the control cells, numerous mitochondria (green fluorescence) could be seen surrounding individual nuclei (blue fluorescence), and mitochondrial lengths were longer (fiberlooking mitochondria in the first column of Fig. (2)). However, both 0.2 and $0.4 \mathrm{~J} / \mathrm{cm}^{2} \mathrm{UVB}$-exposed cells showed shorter mitochondria, fewer fiber-looking mitochondria and mostly fragmented and merged mitochondria (see second column of Fig. (2)). Also, the results for the 0.2 and 0.4 $\mathrm{J} / \mathrm{cm}^{2}$ exposed cells showed reduced cell populations in comparison with the control group. The results for the 0.9 $\mathrm{mm}$ and $1.5 \mathrm{~mm}$ thickness IOL covered cell groups also corresponded with the Alamar blue assay results, supporting the lack of significant morphological changes to the mitochondria (long fiber-looking mitochondria in the third and forth column of Fig. (2)). This inference is based on the common view that the Alamar blue assay is a measure of mitochondrial activity $[27,28]$.

\section{Morphology of Nuclei}

Non-irradiated cultured RPE cells (control cells) exhibited no morphological nuclear changes (first column of Fig. (3)). Increasing the energy level of UVB radiation from 0.2 to $0.4 \mathrm{~J} / \mathrm{cm}^{2}$ to the cells, without the protection of IOL material, reduced the number of cells attached to the slide due to cell death (second column of Fig. (3)). At a level of $0.2 \mathrm{~J} / \mathrm{cm}^{2} \mathrm{UVB}$, irradiated cell nuclei seemed expanded in size, and did not show DNA fragmentation (second column, first row of Fig. (3)). Also, $0.2 \mathrm{~J} / \mathrm{cm}^{2} \mathrm{UVB}$ irradiated cells exhibited bright rings of DNA around the periphery of the nucleus (second column, first row of Fig. (3)). However, 0.4 $\mathrm{J} / \mathrm{cm}^{2}$ UVB irradiated cell nuclei seemed condensed and shrunken in size. They did not show DNA fragmentation (second column, second row of Fig. (3)). The results of 0.9 $\mathrm{mm}$ and $1.5 \mathrm{~mm}$ thickness IOL material covered cell groups also corresponded to the above Alamar blue assay and confocal microscopy results, showing no significant morphological nuclear changes and showing similar morphology and number of cells as control cell groups in both the 0.2 and 0.4 $\mathrm{J} / \mathrm{cm}^{2}$ UVB irradiation groups (third and fourth column of Fig. (3)).
$0.2 \mathrm{~J} / \mathrm{cm} 2$ broadband UV- B irradiated ARPE- 19

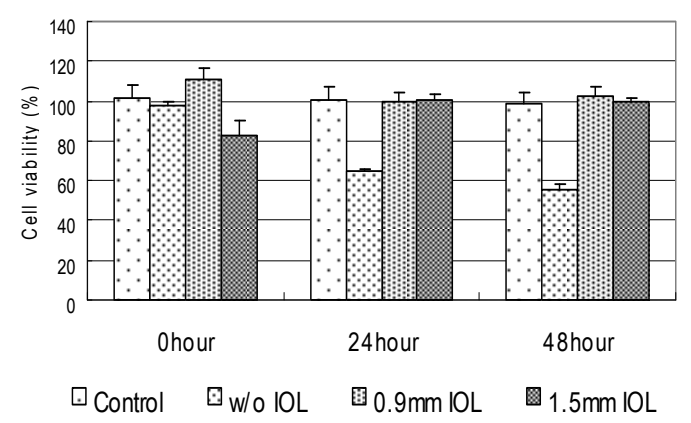

$0.4 \mathrm{~J} / \mathrm{cm} 2$ broadband UV- B irradiated ARPE- 19

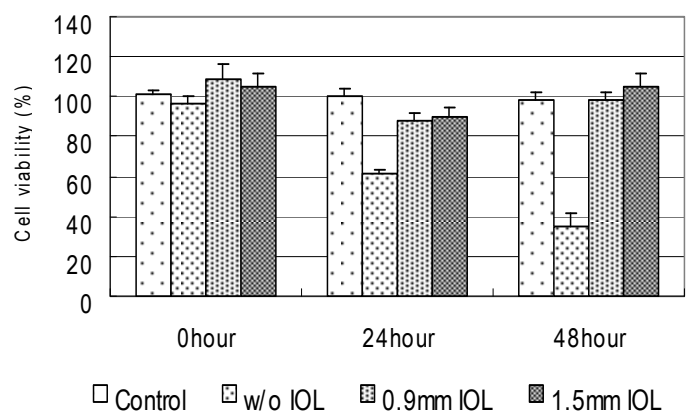

Fig. (1). Cell viability (\%) is shown as a function of time (0, 24, and 48 hours) for RPE cells irradiated with broadband UV-B (Fig. (1a): 0.2 , and Fig. (1b): $0.4 \mathrm{~J} / \mathrm{cm}^{2}$ ), as revealed by the Alamar blue assay. Cell viability was expressed as a percent of non-UVB exposed cells (\% of control). * indicates significant differences as compared to controls $(\mathrm{p}<0.05)$. 
CONTRL

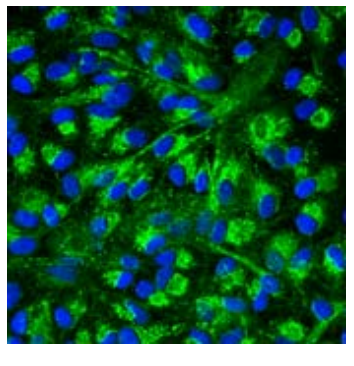

$0.2 \mathrm{~J} / \mathrm{cm}^{2}$

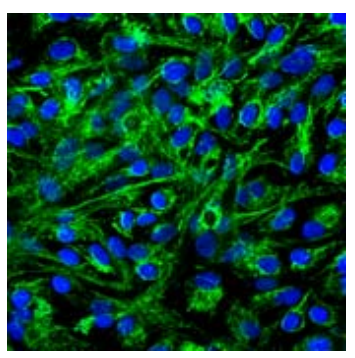

w/o IOL
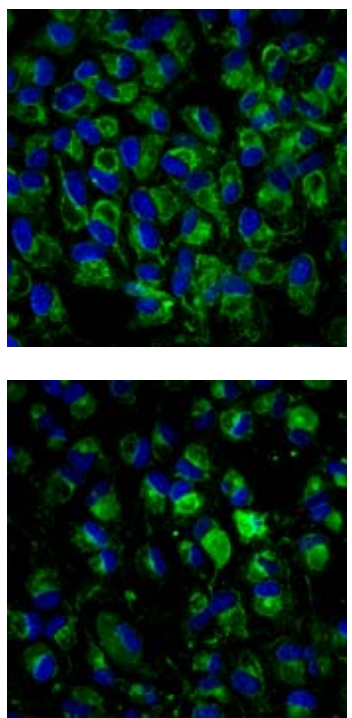

$0.9 \mathrm{~mm} \mathrm{IOL}$
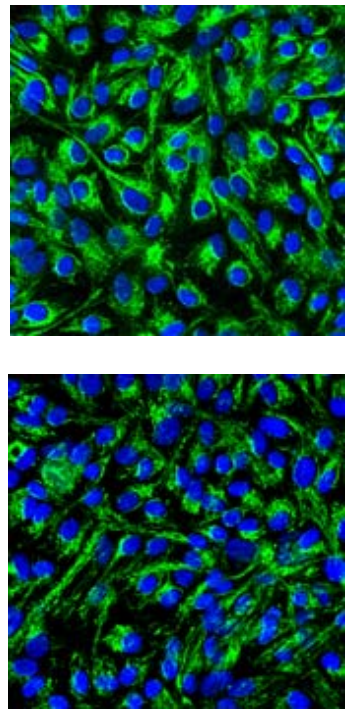

$1.5 \mathrm{~mm} \mathrm{IOL}$
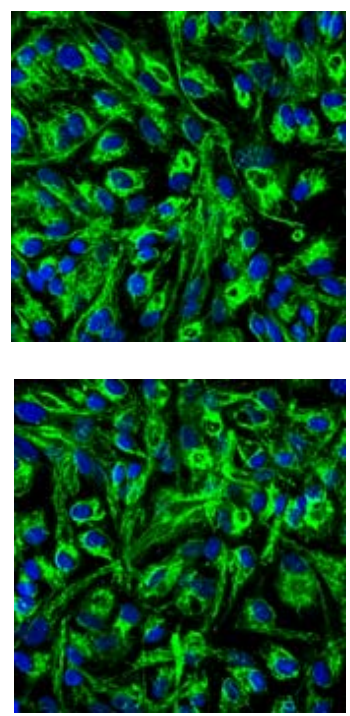

Fig. (2). Representative confocal laser scanning micrographs showing the effect of UV-B $\left(0.2\right.$ and $\left.0.4 \mathrm{~J} / \mathrm{cm}^{2}\right)$ at 24 hours on distribution of the Rhodamine 123 stained mitochondria (green) and Hoechst 33342 stained nuclei (blue) in RPE cells. Overall, increasing the energy level of UVB radiation from 0.2 to $0.4 \mathrm{~J} / \mathrm{cm}^{2}$ resulted in sparser mitochondria, indicating degradation of mitochondria.

CONTROL

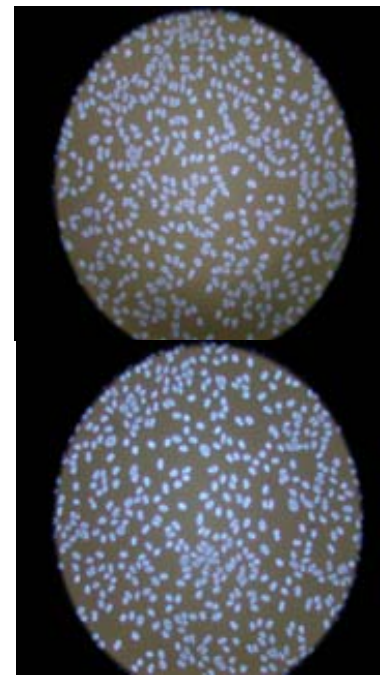

w/O IOL

$0.9 \mathrm{~mm} \mathrm{IOL}$

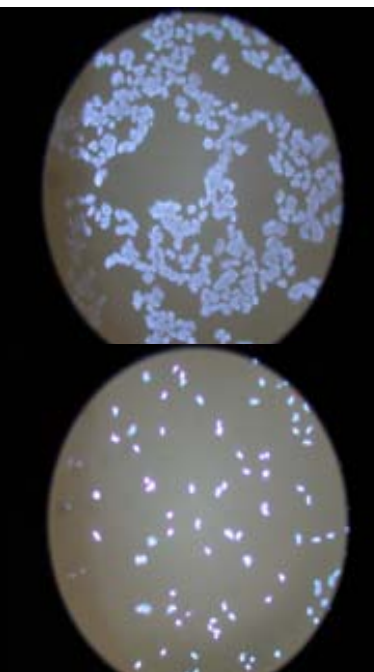

$1.5 \mathrm{~mm} \mathrm{IOL}$

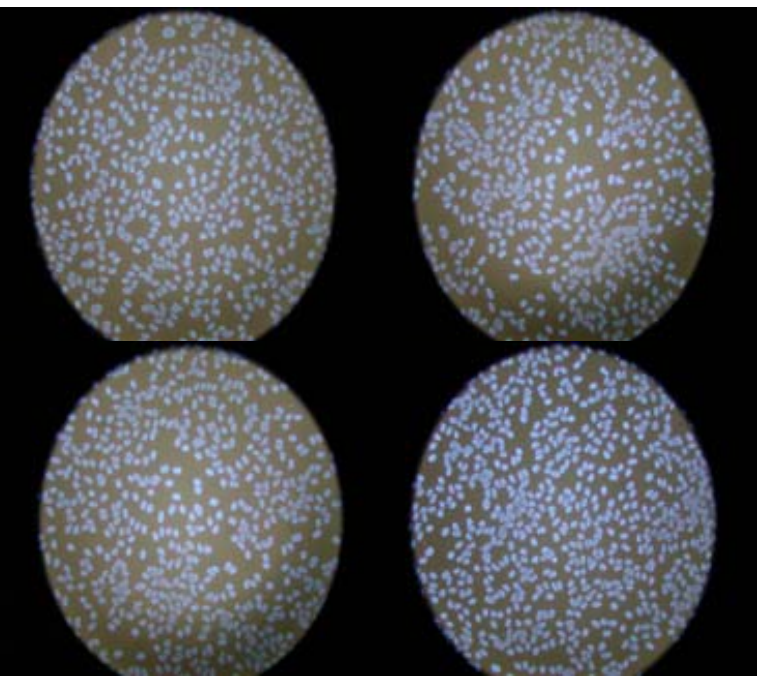

Fig. (3). Effect of 0.2 and $0.4 \mathrm{~J} / \mathrm{cm}^{2}$ broadband UVB exposure at 24 hours on the nuclear morphology of RPE cells (eight groups) as revealed by Hoechst 33342 staining and fluorescence microscopy). At a level of $0.2 \mathrm{~J} / \mathrm{cm}^{2} \mathrm{UVB}$, irradiated cell nuclei seemed expanded in size, and $0.4 \mathrm{~J} / \mathrm{cm}^{2} \mathrm{UVB}$ irradiated cell nuclei seemed condensed and shrunken in size.

\section{Phagocytotic Activity}

Phagocytotic activity is presented as mean intensity of fluorescence of the ingested microspheres in the cells. Nine different spots of each cell plate were randomly selected, and the intensity of each spot was calculated. The final intensity value of each cell group was the average value of the 9 different spots. The ingestion of red fluorescent microbeads $(580 / 605 \mathrm{~nm})$ into RPE cells is shown in the confocal microscopic images (original magnification $\times 40$ oil, $\times 2$ zoom, $\mathrm{Z}$ stack) (Fig. 4). The images were taken using the $\mathrm{Z}$ stack function of the confocal microscope and the middle $Z$ slide image was chosen for analysis. The overall phagocytotic activity assay results are shown in Fig. (5). The control cells have significantly greater capacities for uptake than the 0.2 and $0.4 \mathrm{~J} / \mathrm{cm}^{2}$ UVB exposed cell groups $(\mathrm{p}<0.05)$, while the IOL material covered cell groups (both $0.9 \mathrm{~mm}$ and 1.5 $\mathrm{mm}$ thickness) showed no significant differences from the control cell groups (Fig. 5). This phagocytotic assay result corresponds with the above 3 assay results, indicating that both IOL materials $(0.9 \mathrm{~mm}$ and $1.5 \mathrm{~mm})$ block UVB radiation very effectively. 


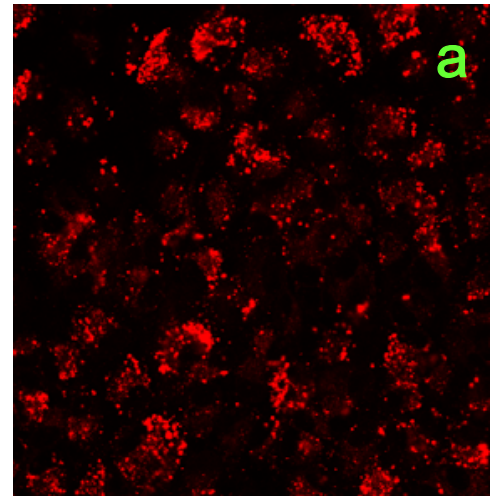

$32.7 \pm 2.9 \quad(n=9)$

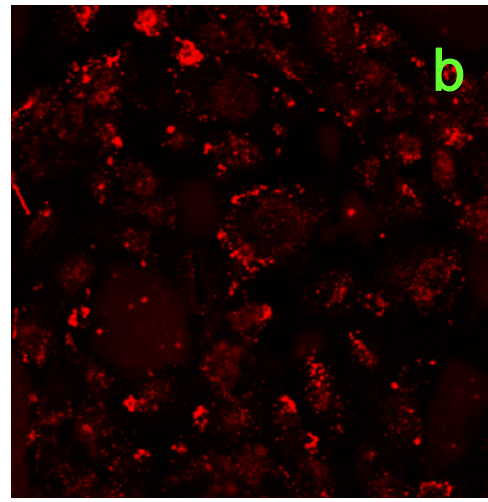

$23.3 \pm 2.5 \quad(n=9)$

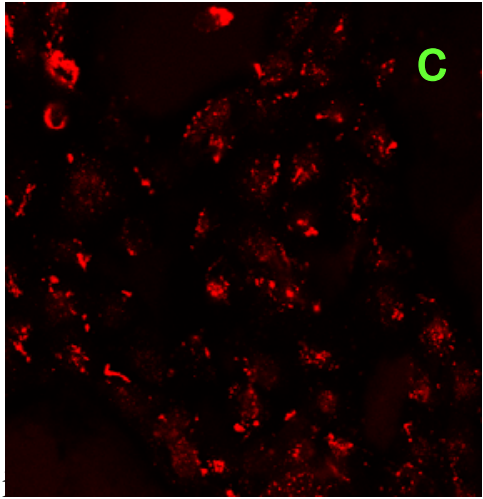

$20.1 \pm 2.4 \quad(n=9)$

Fig. (4). Representative confocal laser scanning micrographs showing the effect of UV-B $\left(0.2\right.$ and $\left.0.4 \mathrm{~J} / \mathrm{cm}^{2}\right)$ at 48 hours on the distribution of red fluorescent microspheres in RPE cells. Numbers on the right are the average intensity of nine different spots of each cell group.

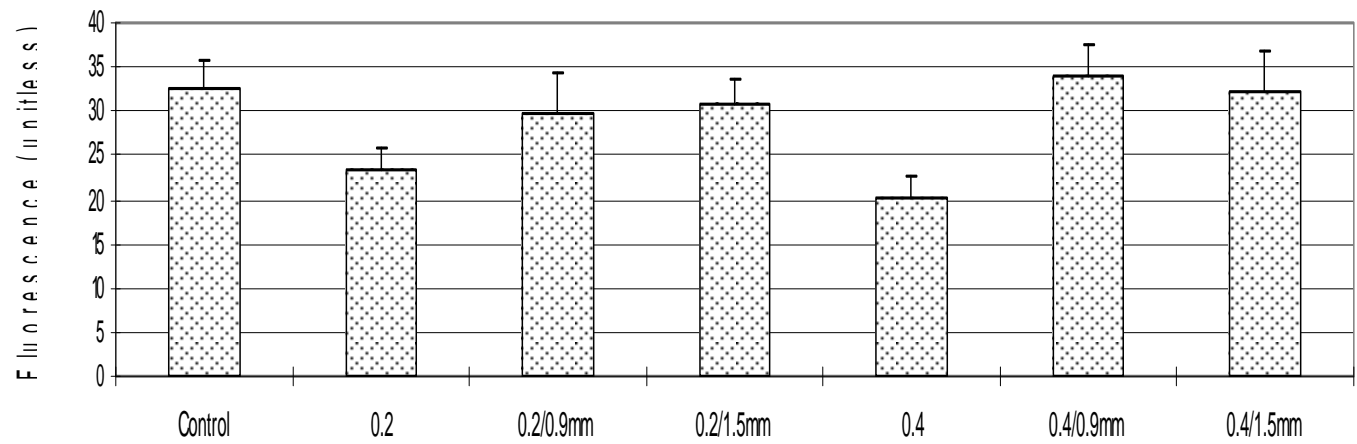

Fig. (5). Effect of 0.2 and $0.4 \mathrm{~J} / \mathrm{cm}^{2}$ broadband UV-B exposure at 48 hours on the phagocytotic activity of RPE cells as revealed by fluorescent microbeads $(0.1 \mu \mathrm{m})$ and flow cytometry. Phagocytotic activity was expressed as the average intensity of nine different RPE images. * indicates significant differences as compared to controls $(\mathrm{p}<0.05)$. In this graph, only seven cell groups are shown since two untreated control groups are combined.

\section{DISCUSSION AND CONCLUSION}

The results of this study demonstrate that broadband UVB radiation damage of RPE cells in culture can be evaluated using four assays; the Alamar blue assay, Rhodamine 123 staining, the Hoestch assay, and a phagocytotic activity assay. Also, the UV blocking efficiency of commercially available IOL materials can be tested using this biological assay model. The results clearly demonstrate that UVB radiation can cause significant decreases in RPE cell viability as well as phagocytotic activity of retinal outer segments by RPE cells. In addition, the results showed that UVB radiation can also induce the degradation of DNA and mitochondria in cultured RPE cells. However, two different thicknesses of IOL material sheets $(0.9 \mathrm{~mm}$ and $1.5 \mathrm{~mm})$ showed very effective UV blocking ability, allowing no cellular damage at all.

There have been many studies that have focused only on the spectral transmittance characteristics of various IOLs to verify their anti-UV efficacy. For example, Mainster measured the spectral transmittance (between $300 \mathrm{~nm}$ and 500 $\mathrm{nm})$ of 16 implantable intraocular lenses from 12 manufacturers and described the importance of using ultravioletabsorptive intraocular lenses to protect pseudophakic patients from photic retinopathy [6]. Also, Lin et al. ana- lyzed the spectral transmittance (from $200 \mathrm{~nm}$ to $800 \mathrm{~nm}$ ) of various lenses (spectacle lenses, contact lenses, and intraocular lenses) to clarify their ultraviolet-blocking efficacy [7]. In addition, there are clinical reports involving postoperative measurements of patients who have received intraocular implants. These include measurements of visual acuity, the occurrence of post operative sight-threatening adverse reactions, and the evaluation of long-term safety and efficacy of implanted ultraviolet absorbing intraocular lenses [29].

It is well known that ultraviolet radiation can produce photochemical lesions in the neural retina and RPE cells, including morphometric cellular changes and DNA damage [15, 30-32]. However, there are fewer studies showing the cytotoxic effects of UV radiation on retina cells in terms of cell biology and physiology. The cellular and molecular mechanisms of ultraviolet-induced retinal cell damage are important to understand how ultraviolet radiation may affect vision.

Alamar blue is a fluometric indicator of cellular metabolic activity, and it is an ideal test for in vitro cell proliferation and cytotoxicity [22]. In the present study, cells analyzed by the Alamar blue assay after UV iradiation showed dose and time dependent decreases in cellular 
viability. A decrease in the Alamar blue fluorescence readings is a direct measure of the decline in cellular metabolic activity due to loss of appropriate cytoplasmic milieu from the photo-oxidative effect of the UV radiation [36]. Hightower and McCready explained that free radicals are often generated by UV photo-oxidation [37]. The phenomenon of photo-oxidation might have caused the impairment of metabolic activity in the cells. The Alamar blue assay, which is non-radioactive, has been used in in vitro photocytotoxicity studies of human RPE, cultured ocular lenses (bovine and porcine), mouse neural crest cells, and human keratinocytes [18, 36, 38-41]. Findings from these studies support the use of the Alamar blue as a sensitive assay for monitoring UV-induced changes in intracellular mitochondrial, cytoplasmic and nuclear integrity, all of which are measures of cellular viability [36].

Rhodamine 123 taken up specifically by mitochondria of living cells can be used as a supravital mitochondrial probe, discriminating between cycling and quiescent cells and having application in sorting functionally distinct cell subpopulations [42]. In the present study, cells analyzed after staining with Rhodamine 123 after UV irradiation showed that by increasing the energy level of UVB radiation, a progressive increase in morphological change, was observed, along with an increased degradation of mitochondria (mostly fragmented and merged mitochondria). Positively charged Rhodamine 123 seems to bind to the high electronegativity of the intact mitochondrial membranes [42]. Therefore, the intensity of mitochondrial staining may correlate with the activity of the oxidoreductive complexes responsible for the maintenance of the electronegativity of the mitochondrial membrane. Thus, Rhodamine 123 may be a direct marker of energy-supplying metabolic processes [43]. Mitochondria represent a primary site of phototoxicity induced by UV radiation in a variety of animal models [33-35]. Also, measurements of mitochondrial deficiencies in living cells by Rhodamine 123 fluorescent micrographs have been used in many in vitro photocytotoxicity studies of human corneal epithelial cells, carcinoma cells, RPE cells, and keratinocytes [16-18, 44-46]. Findings from these studies support the use of Rhodamine 123 as a sensitive mitochondrial probe for monitoring UV-induced mitochondrial changes in living cells.

Hoechst 33342 nucleic acid stain is a popular cellpermeant nuclear counter stain that emits blue fluorescence when bound to dsDNA [47]. This dye is often used to distinguish condensed pycnotic nuclei in apoptotic cells. In the present study, cells analyzed with Hoechst 33342 after UV irradiation showed progressive nuclear morphological change with size expansion for $0.2 \mathrm{~J} / \mathrm{cm}^{2}$ UVB irradiated cells, and condensation in size for $0.4 \mathrm{~J} / \mathrm{cm}^{2} \mathrm{UVB}$ irradiated cells. Also, $0.2 \mathrm{~J} / \mathrm{cm}^{2} \mathrm{UVB}$ irradiated cells exhibited bright rings of DNA around the periphery of expanded nuclei, which is regarded as the early stage of apoptosis [48]. Apoptosis in animal cells is characterized by chromatin condensation and DNA fragmentation [49], but in the present study there was no DNA fragmentation (data not shown) while there was chromatin condensation in the 0.4 $\mathrm{J} / \mathrm{cm}^{2}$ UVB treated cell group. Thus, more detailed studies are necessary to establish whether cell damage induced by UV radiation is apoptotic or non-apoptotic. The measurement of condensed pycnotic nuclei from Hoechst 33342 fluorescent micrographs has been used in in vitro photocytotoxicity studies of rat hepatocytes, Chinese hamster ovary cells, Xenopus XTC-2 cells, and B-cell hybridoma [50-53]. Findings from these studies support the use of Hoechst 33342 as a sensitive nuclui morphological marker for monitoring UV-induced cell damage.

The RPE performs several crucial functions important for maintaining the outer retina, including phagocytosis of the distal tips of outer segments, recycling of visual pigment, and transferring nutrients from the choriocapillaris to the neural retina $[26,54,55]$. In vivo, approximately $3 \%-5 \%$ of the distal tips of photoreceptor outer segments are shed daily, and proper RPE phagocytosis is necessary to maintain the health and integrity of the neural retina and choriocapillaris $[26,54,56]$. A decrease in phagocytic ability may be associated with an increase in RPE melanogenesis, and clinically, RPE hyperpigmentation is a risk factor for the development of ARMD [57, 58]. In the present study, fluorescent microspheres were used to observe the effects of UVB radiation on RPE cell phagocytotic activity. Increasing the energy level of UVB radiation induced decreased phagocytotic activity of RPE cells. Although it is not clear which molecular change is responsible for a decline in RPE phagocytosis ability, it is known that UV-induced http://www.ncbi.nlm.nih.gov/ pubmed/9724002? ordinalpos $=5 \&$ itool $=$ EntrezSystem 2. PEntr ez.Pubmed.Pubmed_ResultsPanel.Pubmed_RVDocSumlipof uscin accumulation in RPE cells reduces their phagocytic capacity [57]. Measurements of ingestion by RPE cells using fluorescent microspheres have been used in many in vitro photocytotoxicity studies of rabbit, bovine, and human RPE cells $[18,58,59]$. Findings from these studies as well as the current one indicate that the use of fluorescent microspheres may be a sensitive tool for monitoring UV-induced changes in phagocytitic activity of RPE cells.

In conclusion, the results of this study have demonstrated that the Alamar blue assay, confocal microscopy with Rhodamine123 staining, Hoechst assay, and phagocytotic activity assay showed that two thickness of an IOL material provide effective RPE cell protection from UVB radiation. These four assays together can be used as a sensitive, and meaningful in vitro biomarker method not only for evaluating IOL effectiveness, but also for evaluating RPE function after UV irradiation.

\section{ACKNOWLEDGEMENTS}

This research was supported by the National Sciences and Engineering Research council of Canada and Bausch \& Lomb, Inc., Rochester, NY, USA. We thank Bausch \& Lomb, Inc., Rochester New York, for providing the IOL materials.

\section{ABBREVIATIONS}
ACGIH $=$ American Conference of Governmental Industrial Hygienist
ANOVA $=$ Analysis of variance
ARMD $=$ Age-related macula degeneration
ATCC $=$ American Type Culture Collection 


$$
\begin{array}{ll}
\text { CLSM }= & \text { Confocal laser scanning microscope } \\
\text { DMEM }= & \text { Dulbecco's Modified Eagle's Medium } \\
\text { HEPES } & \text { N-2-hydroxyethylpiperazine-N'-2- } \\
& \text { ethanesulfonic acid } \\
\text { IOL } & =\text { Intraocular lens } \\
\text { ITS } & =\text { Insulin-transfferin-sodium selenite } \\
\text { PBS } & =\text { Phosphate buffered saline } \\
\text { RPE } & =\text { Retinal pigment epithelium } \\
\text { v/v } & =\text { Volume per volume }
\end{array}
$$

\section{REFERENCES}

[1] Boettner EA, Wolter JR. Transmission of the ocular media. Invest Ophthalmol Vis Sci 1962; 1: 776-83.

[2] Ellerin BE, Nisce LZ, Roberts CW, et al. The effect of ionizing radiation on intraocular lenses. Int J Radiat Oncol Biol Phys 2001; 51: 184-208.

[3] Mainster MA. Spectral transmittance of intraocular lenses and retinal damage from intense light sources. Am J Ophthalmol 1978; 85: $167-70$.

[4] Ham WT Jr, Ruffolo JJ Jr, Mueller HA, Guerry D $3^{\text {rd }}$. The nature of retinal radiation damage: dependence on wavelength, power level and exposure time. Vision Res 1980; 20: 1105-11.

[5] Mainster MA, Ham WT Jr, Delori FC. Potential retinal hazards. Instrument and environmental light sources. Ophthalmology 1983; 90: 927-32.

[6] Mainster MA. The spectra, classification, and rationale of ultraviolet-protective intraocular lenses. Am J Ophthalmol 1986; 102: $727-32$

[7] Lin KK, Lin YC, Lee JS, Chao AN, Chen HSL. Spectral transmission characteristics of spectacle, contact, and intraocular lenses. Ann Ophthalmol 2002; 34: 206-15.

[8] Mainster MA. Intraocular lenses should block UV radiation and violet but not blue light. Arch Ophthal 2005; 123: 550-5.

[9] Mainster MA. Violet and blue light blocking intraocular lenses: photoprotection versus photoreception. Br J Ophthalmol 2006; 90: 784-92.

[10] Thoms M, Fishman GA, Meulen DV. Spectral transmission characteristics of intraocular and aphakic contact lenses. Arch Ophthal 1983; 101: 92-3.

[11] Alapetite C, Wachter T, Sage E, Moustacchi E. Use of the alkaline comet assay to detect DNA repair deficiencies in human fibroblasts exposed to UVC, UVB, UVA and gamma-rays. Int J Radiat Biol 1996; 69: 359-69.

[12] Hiramitsu T, Armstrong D. Preventive effect of antioxidants on lipid peroxidation in the retina. Ophthalmic Res 1991; 23: 196-203.

[13] Augustin AJ, Hunt S, Breipohl W, Böker T, Spitznas M. Influence of oxygen free radicals and free radical scavengers on the growth behaviour and oxidative tissue damage of bovine retinal pigment epithelium cells in vitro. Graefes Arch Clin Exp Ophthalmol 1996; 234: 58-63.

[14] Kielbassa C, Roza L, Epe B. Wavelength dependence of oxidative DNA damage induced by UV and visible light. Carcinogenesis 1997; 18: 811-6.

[15] Patton WP, Chakravarthy U, Davies RJ, Archer DB. Comet assay of UV-induced DNA damage in retinal pigment epithelial cells. Invest Ophthalmol Vis Sci 1999; 40: 3268-75.

[16] Shimmura S, Tsubota K. Ultraviolet B-induced mitochondrial dysfunction is associated with decreased cell detachment of corneal epithelial cells in vitro. Invest Ophthalmol Vis Sci 1996; 38: 620-6.

[17] Bantseev V, Youn HY. Mitochondrial "movement" and lens optics following oxidative stress from UV-B irradiation: cultured bovine lenses and human retinal pigment epithelial cells (ARPE-19) as examples. Ann N Y Acad Sci 2006; 1091: 17-33.

[18] Youn HY, Bantseev V, Bols NC, Cullen AP, Sivak JG. In vitro assays for evaluating the ultraviolet B-induced damage in cultured human retinal pigment epithelial cells. J Photochem Photobiol B 2007; 88: 21-8.
[19] Nielsen LK, Reid S, Greenfield PF. Cell cycle model to describe animal cell size variation and lag between cell number and biomass dynamics. Biotechnol Bioeng 2000; 56: 372-9.

[20] American Conference of Governmental Industrial Hygienists (ACGIH). Threshold limit values for chemical substances and physical agents and biological exposure indices. Cincinnati, $\mathrm{OH}$ : USA 2006; pp. 164-70.

[21] Oriowo OM, Cullen AP, Schirmer K, Chou BR, Bols NC, Sivak JG. Evaluation of a porcine lens and fluorescence assay approach for in vitro ocular toxicological investigations. Altern Lab Anim 2002; 30: 505-13.

[22] O'Brien J, Wilson I, Orton T, Pognan F. Investigation of the Alamar Blue (resazurin) fluorescent dye for the assessment of mammalian cell cytotoxicity. Eur J Biochem 2000; 267: 5421-6.

[23] Dayeh VR, Schirmer K, Lee LEJ, Bols NC. The use of fish-derived cell lines for investigation of environmental contaminants. Current protocols toxicology. Wiley: New York 2003; pp. 1-17.

[24] Durand RE, Olive PL. Cytotoxicity, Mutagenicity and DNA damage by Hoechst 33342. J Histochem Cytochem 1982; 30: 1116.

[25] Darzynkiewicz Z, Traganos F, Staiano-Coico L, Kapuscinski J, Melamed MR. Interaction of rhodamine 123 with living cells studied by flow cytometry. Cancer Res 1982; 42: 799-806.

[26] Young RW, Bok D. Participation of the retinal pigment epithelium in the rod outer segment renewal process. J Cell Biol 1969; 42: 392-403.

[27] Abu-Amero KK, Bosley TM. Detection of mitochondrial respiratory dysfunction in circulating lymphocytes using resazurin. Arch Pathol Lab Med 2005; 129: 1295-8.

[28] Zhang HX, Du GH, Zhang JT. Assay of mitochondrial functions by resazurin in vitro. Acta Pharmacol Sin 2004; 25: 385-9.

[29] Steinert RF, Giamporcaro JE, Tasso VA. Clinical assessment of long-term safety and efficacy of a widely implanted silicone intraocular lens material. Am J Ophthalmol 1997; 123: 17-23.

[30] Noell WK. Possible mechanisms of photoreceptor damage by light in mammalian eyes. Vision Res 1980; 20: 1163-71.

[31] Gorgels TGMF, van Norren D. Ultraviolet and green light cause difference types of damage in rat retina. Invest Ophthalmol Vis Sci 1995; 36: 851-63.

[32] Tratsk KS, Thanos S. UV irradiation causes multiple cellular changes in cultured human retinal pigment epithelium cells. Graefes Arch Clin Exp Ophthalmol 2003; 241: 852-9.

[33] Bastianon C, Zanoni R, Miolo G, Caffieri S, Reddi E Mitochondria and plasma membrane as targets of UVA-induced toxicity of neuroleptic drugs fluphenazine, perphenazine and thioridazine. Int J Biochem Cell Biol 2005; 37: 901-8.

[34] $\mathrm{Lu} \mathrm{X}, \mathrm{Wu}$ RS. Ultraviolet damages sperm mitochondrial function and membrane integrity in the sea urchin Anthocidaris crassispina. Ecotoxicol Environ Saf 2005; 61: 53-9.

[35] Paz ML, Maglio GDH, Weill FS, Bustamante J, Leoni J. Mitochondrial dysfunction and cellular stress progression after ultraviolet B irradiation in human keratinocytes. Photodermatol Photoimmunol Photomed 2008; 24: 115-22.

[36] Oriowo OM. AlamarBlue bioassay for cellular investigation of UV-induced crystalline lens damage. Ophthalmic Physiol Opt 2003; 23: 307-14.

[37] Hightower K, McCready J. Mechanisms involved in cataract development following near-ultraviolet radiation of cultured lenses. Curr Eye Res 1992; 11: 679-89.

[38] Youn HY, Moran KL, Oriowo OM, Bols NC, Sivak JG. Surfactant and UV-B-induced damage of the cultured bovine lens. Toxicol In Vitro 2004; 18: 841-52.

[39] Oriowo OM, Cullen AP, Sivak JG. Impairment of eye lens cell physiology and optics by broadband ultraviolet A-ultraviolet B radiation. Photochem Photobiol 2002; 76: 361-7.

[40] Hosaka E, Soma Y, Kawa Y, et al. Effects of ultraviolet light on melanocyte differentiation: studies with mouse neural crest cells and neural crest-derived cell lines. Pig Cell Res 2004; 17: 150-7.

[41] Reid L, Clothier RH, Khammo N. Hydrogen peroxide induced stress in human keratinocytes and its effect on bithionol toxicity. Toxicol In Vitro 2001; 15: 441-5.

[42] Darzynkiewicz Z, Staiano-Coico L, Melamed MR. Increased mitochondrial uptake of rhodamine 123 during lymphocyte stimulation. Proc Natl Acad Sci USA 1981; 78: 2383-7.

[43] Schneckenburger H, Gessler P, Pavenstädt-Grupp I. Measurements of mitochondrial deficiencies in living cells by 
microspectrofluorometry. J Histochem Cytochem 1992; 40: 15738.

[44] Shimmura S, Tadano K, Tsubota K. UV dose-dependent caspase activation in a corneal epithelial cell line. Curr Eye Res 2004; 28 : $85-92$.

[45] Shea CR, Wimberly J, Hasan T. Mitochondrial phototoxicity sensitized by doxycycline in cultured human carcinoma cells. J Invest Dermatol 1986; 87: 338-42.

[46] Banerjee G, Gupta N, Kapoor A, Raman G. UV induced bystander signaling leading to apoptosis. Cancer Lett 2004; 223: 275-84.

[47] Mocharla R, Mocharla H, Hodes ME. A novel, sensitive fluorometric staining technique for the detection of DNA in RNA preparations. Nucleic Acids Res 1987; 15: 10589.

[48] Kressel M, Groscurth P. Distinction of apoptotic and necrotic cell death by in situ labeling of fragmented DNA. Cell Tissue Res 1994; 278: 549-56.

[49] Ricci MS, Zong WX. Chemotherapeutic approaches for targeting cell death pathways. Oncologist 2006; 11: 342-57.

[50] Worner W, Schrenk D. Influence of liver tumor promoters on apoptosis in rat hepatocytes induced by 2 -acetylaminofluorene, ultraviolet light, or transforming growth factor beta 1 . Cancer Res 1996; 56: 1272-8.

[51] Baumstark-Khan C, Hentschel U, Nikandrova Y, Krug J, Horneck G. Fluorometric analysis of DNA unwinding (FADU) as a method for detecting repair-induced DNA strand breaks in UV-irradiated mammalian cells. Photochem Photobiol 2000; 72: 477-84.
[52] Davis SK, Bardeen CJ. Cross-linking of histone proteins to DNA by UV illumination of chromatin stained with Hoechst 33342 . Photochem Photobiol 2003; 77: 675-9.

[53] Souvannavong V, Lemaire C, Brown S, Adam A. UV irradiation of a B-cell hybridoma increases expression of alkaline phosphatase: involvement in apoptosis. Biochem Cell Biol 1997; 75: 783-8.

[54] La Vail MM. Rod outer segment disk shedding in rat retina: relationship to cyclic lighting. Science 1976; 194: 1071-4.

[55] Young RW. The renewal of photoreceptor cell outer segments. J Cell Biol 1967; 33: 61-72.

[56] Young RW. The daily rhythm of shedding and degradation of cone outer segment membranes in the lizard retina. J Ultrastruct Res 1977; 61: 172-85.

[57] Sundelin S, Wihlmark U, Nilsson SE, Brunk UT. Lipofuscin accumulation in cultured retinal pigment epithelial cells reduces their phagocytic capacity. Curr Eye Res 1998; 17: 851-7.

[58] Nilsson SE, Sundelin SP, Wihlmark U, Brunk UT. Aging of cultured retinal pigment epithelial cells: oxidative reactions, lipofuscin formation and blue light damage. Doc Ophthalmol 2003; 106: 13-6.

[59] Seagle BL, Gasyna EM, Mieler WF, Norris JR Jr. Photoprotection of human retinal pigment epithelium cells against blue lightinduced apoptosis by melanin free radicals from Sepia officinalis. Proc Natl Acad Sci USA 2006; 103: 16644-8. 